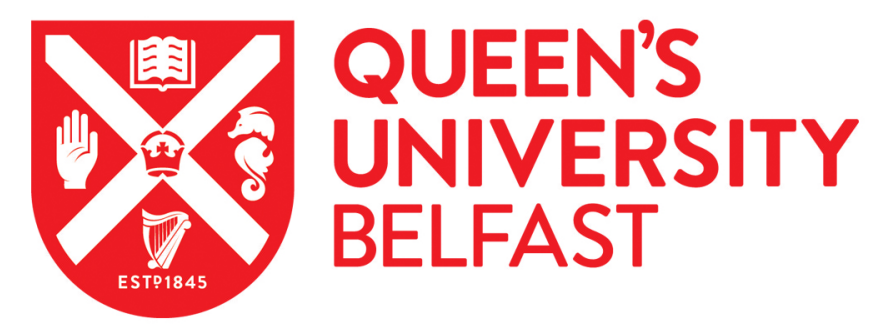

\title{
Narrating Entanglements: Rethinking the Local/Global Divide in Ethnographic Migration Research
}

Johnson, H. L. (2017). Narrating Entanglements: Rethinking the Local/Global Divide in Ethnographic Migration Research. International Political Sociology, 10(4), 383-397. https://doi.org/10.1093/ips/olw021

\author{
Published in: \\ International Political Sociology
}

Document Version:

Peer reviewed version

Queen's University Belfast - Research Portal:

Link to publication record in Queen's University Belfast Research Portal

\begin{abstract}
Publisher rights
Copyright the author 2016. Published by Oxford University Press on behalf of the International Studies Association. All rights reserved. This is a pre-copyedited, author-produced version of an article accepted for publication in International Political Sociology following peer review. The version of record is available online at: https://doi.org/10.1093/ips/olw021.
\end{abstract}

\section{General rights}

Copyright for the publications made accessible via the Queen's University Belfast Research Portal is retained by the author(s) and / or other copyright owners and it is a condition of accessing these publications that users recognise and abide by the legal requirements associated with these rights.

Take down policy

The Research Portal is Queen's institutional repository that provides access to Queen's research output. Every effort has been made to ensure that content in the Research Portal does not infringe any person's rights, or applicable UK laws. If you discover content in the Research Portal that you believe breaches copyright or violates any law, please contact openaccess@qub.ac.uk. 


\title{
Narrating Entanglements: \\ Rethinking the Local/Global Divide in Ethnographic Migration Research
}

\author{
Heather L. Johnson, Queen's University Belfast
}

\begin{abstract}
This paper interrogates the emerging practices of narrative methods in research that focuses on mobility and migration. It seeks to understand how these methods enable a conceptualisation of global politics which challenges the global/local divide, revealing instead complex entanglements through which the local and the global are mutually constituted. Focusing in particular on the primacy of narrative, and on the concept of 'translation', the paper argues that participants in research author narratives in ways that reveal alternative, powerful accounts of global politics that are meaning-making and demand an understanding of 'local' knowledges as valid and important insights into how global politics is understood. Ultimately, these methods engage the heterogenous, multiple, and ultimately fully relational narratives of individuals who are autonomous and creative, and the ways these accounts interrupt the dominant narratives of how the world is politically understood - and is politically practiced.
\end{abstract}

Keywords: methodology, global politics, migration, narrative 
Recent scholarship in migration studies has emphasized the need to account for the direct, lived experiences of migrants themselves (cf. Doty 2006; Hyndman 2010; Johnson 2014; Nyers 2006; McNevin 2006; Rygiel 2008). To understand the 'how' and 'why' of irregular migration, to understand and engage with its implications and consequences, the experiences and voices of migrants themselves are crucial. It is engagement at this level that enables us to give context and content to the policies that govern cross-border migration; the everyday lives of migrants who encounter (or avoid) security personnel, who live in camps, reception centres, and detention centres - the exceptional spaces of migration - and who challenge state frameworks and law, reveal the politics of security, citizenship, and mobility that shape key parts of our contemporary world.

The paper begins from an assertion of the need to include and consider qualitative research that engages irregular migrants not only as participants, but as authors. My focus, therefore, is on method and research design. It is my intention to use research in migration studies as a starting place and illustration of larger issues about how we consider the politics of voice through research methods, and what implications this has for how we might challenge the separation of the local and global, and so fracture this divide. These questions and dynamics have been important considerations for research in international relations, and particularly in international political sociology, over recent years. They arise from and shape debates about methods informed by ethnography (Marcus 2013; Buroway 2001; Dauphinee 2010; Doty 2006), but also have wider resonance for qualitative and participant-led research. I argue that a consideration of narrative in qualitative work contains within it the potential to interrupt dominant discourses that reify a separation between the 'local' and the 'global' - and so privilege the global as authoritative in shaping our political imagination. In this context, I understand 'local' and 'global' to be more than geographic or 'scalar' concepts. Rather, 'local' here refers to information and 'data' that is specific. It is the lived, experienced, deeply contextual life stories of individuals. The 'local' is the 'everyday', imbued with rich detail of particular places and times. The global, by contrast, is situated as broad, overarching and generalizable, and as disembedded from context - somehow transcending space and time. The global in this sense is related to the universal, and while the distinction might be overly simplistic, it nevertheless has powerful effects. In particular, when the conflation of the local with the specific is set against that of the global and therefore generalizable, I argue that there are striking implications for how we then situate and understand the authority and legitimacy of the voices that speak within each. The local becomes limited, anecdotal, and contained, important in context but not constitutive of the dominant narratives or frameworks of politics of power. These voices are understood to be separate from these frameworks, responding to them or consequent of them rather than essential to their creation and reproduction. 'Global' voices, meanwhile, become powerful in determining our political imaginations; they speak with authority that transcends mundane divides, in the tones and measures of the 'universal', legitimizing and rendering dominant power structures as fixed, unassailable - or as common sense 'reality'. In research that desires to speak of the 'international', or of 'global politics', this divide between global and local reproduces and concretizes the division between elite and marginalized, the powerful who frame and sustain the dominant narrative, and the subaltern, who are silenced within it. For migration, the powerful global actors are those in state policy and in international organisations who govern, regulate, and manage the system; the subaltern, 'local' actors are here the migrants themselves, with specific experiences of the consequences of the migration regime, but seemingly, in this frame, without the power to shape it.

However, in a study of migration that directly engages the 'local' voices of migrants themselves, a different picture emerges of the local and global not as separate, but as entangled and mutually constitutive. Migration that crosses borders - be they political, social or geographical - directly engages with the global, encountering the norms and practices of a regime that works to control 
mobility, preserve borders, and maintain the sovereignty and security of the nation-state. Irregular migration in particular manifests a direct encounter between the autonomy of mobile individuals and the sovereignty of nation-states. I argue that the everyday lives and decisions of migrants, both their mobility and their presence, call into being a global politics that engages fundamental questions of political agency, of exclusion and marginalisation, and of power and resistance. This politics is fractured, experienced in different ways in different places, and so is heterogenous. It is nevertheless connected in patterns of contestation, in actions and experiences that connect to and make use of fundamental political ideas and concepts, including political agency, (human) rights, borders, and sovereignties. In doing so, they are directly implicated in shaping these fundamental political narratives. The crossing of borders is an interruption of the 'global' system of states, and an interruption or fracturing of the discourses, practices, and regimes that sustain it.

Narrative methods enable the researcher to centre the voice of the migrant, to challenge the authorisation of the already powerful, and to contest the silences and silencing of global politics. It is my argument that research that seeks to disrupt and interrupt dominant power structures, to challenge the exclusionary borders between citizen and non-citizen, and to assert the political power of those populations otherwise unaccounted for benefits from an approach that examines the world not as one that is separated by distinct spheres, but in which the local and the global are simultaneous. To achieve this, we must recognize migrants (and participants) as authors of their own narratives, and take these dynamics seriously. What is at stake here are new understandings of the social-political world, and of how the dominant concepts which form the basis of how we describe, understand, and change the world are formed, sustained and challenged. The 'local' and the 'global' interrupt one another, shaping mutual meanings and power relations, and if we are to understanding the shape and consequences of these entanglements of power, we must be attentive to the 'local' not as an alternative to or consequence of the global, but as a manifestation of the global itself. One cannot exist without the other.

This paper will examine these dynamics by building on insights gathered during field research into irregular and asylum migration, and the practices of resistance enacted by migrants in global border spaces. It will proceed in the following way: I first examine the politics of the authorisation of voice, arguing that an 'authorisation of the local' is needed to collapse the distinction between the local and the global, recognising them as co-constitutive with one another. I then suggest that an understanding of narrative that takes seriously the dynamics of what I call here 'translation' is needed, and finish by considering the concept of interruptions as a space for alternative imaginations and change. Bourdieu writes that "theory without empirical research is empty, empirical research without theory is blind" $(1988,774)$. To effectively theorize migration, therefore, the empirical context and experience of migrants themselves must be included. This inclusion, in turn, demands a research design shaped by a theorization of the local and global as entangled and co-constituted. These interruptions not only disrupt the ways in which we understand the world, but also intervene in the shaping of these understandings themselves and thus research participants become not 'informants', but 'authors' - collaborators - in the theorization of both power and politics. They become locally participant in the writing of global narratives.

\section{Authorised Voices: Collapsing the Local and the Global}

In an office in Madrid, a senior official at an international organisation looked at me very seriously after we discussed the research I was conducting, which included interviews with 
irregular migrants, some of whom were waiting for the opportunity to attempt to cross Spain's borders, and some of whom already had. He asked whether I was hoping to get 'a truer account' of their experiences and, while he 'applauded' my efforts to get first-hand perspectives on the issue, he had a word of warning. Be careful, he told me. They'll only tell you what you want to hear (personal interview, Madrid March 2008). The conversation was a direct echo - with remarkable duplication - of a conversation I had had three months earlier, in a much smaller office in the administration compound of a refugee camp in Kibondo, Tanzania. Again in the context of a conversation that sought to explain the components of my field research, and what I was hoping to achieve, the official warned me very seriously that the refugees I spoke to might (and most likely would) misrepresent themselves, exaggerate their stories, and tell only partial accounts, both because they would 'tell me what I want to hear' but also because they wished to achieve some kind of benefit for themselves (personal interview, Kibondo Dec 2007). The warning was that individuals would misrepresent at best, and lie about at worst, their circumstances in order to mobilize my help in their personal struggles for additional resources, or for assistance with resettlement applications.

In neither conversation did I have the impression that the officials I was interviewing were necessarily casting moral aspersions on the character of migrants. This wasn't (simply) a reproduction of the framing of the refugee/migrant as somehow unworthy or suspicious, although it must be said that the dominance of such an assumption within the politics of migration is part of what makes such statements both seemingly easy, and also legitimate. Rather, the statements were direct commentaries on the process and practice of research itself. The warning was that I would not be able to achieve 'objective' or 'reliable' data from migrants, and that I should take careful account of this. These warning were not mobilized with respect to interviews with officials - there was no sense that I might be manipulated by experts or professionals. Migrants, however, occupy a subaltern position within the politics of migration. Their stakes in my research, therefore, were seen as different -as were, perhaps, their understandings of the research process itself. While elites were understood as having an impersonal, detached, and broader understanding of the politics of migration, as able to access, perceive, and shape the global dimensions, the migrants were understood as having a personal stake in the research exchange. The possibility that they would seek to achieve some form of benefit by manipulating the narrative was seen as something I needed to be wary of. Further, migrants were understood as more situated, with a narrower 'local' understanding in comparison to that of the 'global' perspective of the officials.

Embedded in these exchanges is a good deal about the perception of migrants, particularly refugees and asylum seekers, and the narratives they present of their stories and experiences. The discourses of threat and suspicion of migrants are clear. But beneath this, and at the core of the exchange, there are assumptions and expectations about the practice of research itself, what it is meant to achieve, and how it is carried out. Moreover, they stand as strong assumptions not only about who can have an authorised voice, but what particular voices are authorised to speak about. The story isn't a simple one about silence and voice. It is far more complex. The cautions I received from these participants are not isolated, and are not unique to their professional roles as 'officials' in migration politics. They are just as prevalent within the academy as our research is shaped by norms of methodology that continue to hearken to principles of replicability and parsimony, and of objectivity, all of which stand in difficult tension with the qualitative methods, and particularly those that focus on narrative or ethnographic material (Marcus 1995). A focus on grounded, local understanding can mean that contributions from these participants seemingly have little to offer towards a global perspective; their insights, experiences, and life stories are not understood as generalizable which is in turn understood as the 'goal' of political research (King, Keohane and Verba 1994). In these ways the global/local binary is manifest in method itself. 
Our world is not only fractured along national lines, or along state borders, but also across class, race, and gender divides and, particularly for research focused on migration, along lines of political status. The question thus becomes how we can engage with this multiplicity, which is global, without seeing only segregated parts (several different 'locals'). A particular aspect of the lives of those who are marginalized and excluded is that they are seemingly profoundly local; exclusion is a specific experience, and the dynamics of marginalization in one place are entirely different from those of another. Each individual narrative is perceived as limited in scope and insight to only that particular context. Such an assumption, however, is embedded within understandings of power. It relegates the knowledges of any non-elite, non-expert, participant as constrained. At the same time, experts and the elite class, so often the focus of top-down or official research, are seen as entirely capable of providing necessary information about the 'whole', or the global. Participants are not seen as able to narrate 'the world'; rather, they narrate 'their world' - a smaller, contained singularity.

The de-authorisation of voice, therefore, has two dimensions that directly flow from the understanding of the global and the local as separate spheres: first, an aspect of marginalisation and exclusion is to be associated with the 'local' and the specific, rendering such experiences and voices limited and anecdotal rather than universal and authoritative. Exclusion is reproduced along the local/global divide, even when research itself focuses on the lived experience and voice of the marginalised. As a result, even when these voices are recognized and 'heard', they remain constrained to only their own context. The second dimension, therefore, is precisely this: the relegation of marginalized or subaltern voices to the 'local' reproduces their exclusion from shaping the dominant narratives of the global political world.

A binary understanding of politics between the 'local' - lived, contextual, specific - and the global - broad, overarching, generalizable - is maintained. Further, in this binary, the global becomes privileged and authoritative in that, in its breadth, it achieves a sense of universality and relevance, while the local risks being reduced to nothing more than anecdotal. A binary understanding portrays the local/global as separate spheres that act upon one another; to study the local as a separate sphere from the global, the global become concretised into a generalizable whole that is fixed, unchanging, and uncontestable, framing and determining the context of the local. To study the global, the local is similarly fixed in place as mere pieces that come together to form a larger whole, disembedded from their dynamic contexts. If however, we conceptualize the two 'scales' as mutually constitutive, as calling each other into being, a different picture emerges. By putting the local and the global into conversation, and understanding the shifting interplays of each, we can understand the local and global as being manifest simultaneously. The global becomes constituted by the complex heterogenous interweaving of the local; the global gains its meaning from the local, and vice versa. We cannot achieve this, however, without asserting the broader relevance of the local.

Insights from Buroway (2001) are helpful in thinking through how we might collapse the local/global distinction. In what he terms 'global ethnography', scholars in anthropology seek the intersections of remote forces, connections, and imaginations in specific and concrete experiences of the global (147). In this, he builds upon Marcus's (1995) multi-sited ethnography, which follows connections between sites. Buroway argues that the global can only be studied in locality, and contests the abstraction of the global. He writes: "what we understand to be 'global' is itself constituted within the local; it emanates from very specific agencies, institutions and organizations whose processes can be observed first-hand" (150). Further, he asserts that the marginalized are just as important to understandings of global processes as are those who are 'included.' Exclusion is also informative about the currents of global, or globalizing, processes; it is significant what individuals are excluded from, and why. I wish to push this insight further, and to argue that the narratives and voices of the marginalized, assumed to be 'only' local in 
Buroway's frame, and to be excluded from global processes in such a way that exclusion means separation or dislocation from the local, are indeed not separate but productive of the global, even in their exclusion. Their experiences and constructions are directly implicated in the constitution of the global itself; they are products of it, even, and their actions, practices, and desires prompt the responses and policies that shape the dynamic nature of global processes.

I argue that this connection and interaction between local and global can become perceptible through a methodological approach that focuses on narrative, which authorises the voices of the local. The concept of narrative has two senses: first, it has a meta-sense, wherein global politics are shaped and determined by dominant discourses that are directly informed by authorised voices. These voices define the concepts and understandings that drive how we see the world (Milliken 2001). Narrative also operates in a different sense, however, which is traditionally understood as manifesting at the 'local', or the everyday. This sense captures the 'stories we tell' about our lives, grounded in a deep perspective and constructing a particular identity and experience. Here, narrative is about the politics of voice and recognition: who speaks, and who is heard. Attention to these narratives allows the entry of 'unauthorized speakers', those who interrupt the dominant discourse, into the global conversation (Johnson 2014).

To achieve this entry, and so to break down the divide between local and global, the challenge becomes how to connect these detailed accounts, these life stories, to other similar narratives and to larger frameworks within which meaning and understanding can be achieved, albeit tentatively. What interpersonal detail reveals is the empirical content of how people actually experience the world, and the politics that drive it. Engaging directly with ways individuals represent themselves, which is possible through narrative, reveals how they situate themselves within the world, and thus both participate in and contest the dominant discourses that create the world. Such an approach enables us to encounter both the said and unsaid, and to begin to break down the objectified, often abstract and homogenizing, conceptions that we have about categories of people - particularly those who are otherwise unaccounted for politically. In consequence, the political implications of collapsing the distinction between local and global are about who speaks, when, and how - and who is heard, when and how. From this perspective, it is an issue of authorization, and legitimacy.

Connecting local narratives to one another allows us to understand how the global comes to be constituted. A research design that is multi-sited enables these connections to be drawn, but similar challenges arise even when multiple geographical 'sites' aren't present, but multiple 'local' narratives are; both present the challenge of how to deal with a fractured multiplicity. The central tension is how to engage with this multiplicity without simply collapsing it into further generalization, either within existing frameworks or, even, in new ones; this collapse loses the empirical content that grounds the understanding of the global, and re-closes space for intervention. The temptation is always to seek fixity, a static and concrete apprehension that is conflated with what we term 'empirical', so we can return again and again to 'data' or 'findings' that will reliably look the same, enable the same conclusions, and replicate our initial impulses and understanding. We seek certainty, and disengage as a consequence. In this fixity, we find the dichotomy between the global and local. If the global is understood as simply an amalgamation of the local, a coming together of the many contexts and the 'findings' research produces about them, the local is rendered as fixed. In stepping 'up' to the global, the dynamic and shifting character of the local is lost and it becomes merely as series of disembedded examples that are assumed to remain as they are.

The 'fixing' of the local in this way is a consequence of methodological demands from replicability, which treats the empirical itself as fixed, and determinate. Two possible consequences emerge. First, the life-stories and narratives of participants are treated as 
interpretive; they are too subjective for replicability, and so their utility in achieving the 'pieced together' model of the global becomes limited. Alternatively, if these stories are accepted as 'data' that can be treated as 'factual', the agency of the participant drops out entirely. The narrative is seen as an accurate, objective representation of the experience, and of the world. When this fails, or is called into question by concerns that the narrative is being shaped according to a particular political agenda, the model falls apart. The accusation that participants are only saying 'what the researcher wants to hear' is enough to condemn the research as unreliable, and, thus, not helpful in achieving the step-up from the limited local to the generalizable global. The quest for certainty in understanding the global not only dismisses the political agency of participants, but creates the division between local and global itself.

Marcus' (1995) notion of multi-sited ethnography suggests particular ways to think through a research design into multiple-sited studies that have global scope but still benefit from the rich and complex detail of locally embedded and empirically rich research. As an approach that valourizes context and detail, there are lessons that can be drawn from ethnography for other methods, particularly those that focus on narrative, as it has been adopted, albeit often in more limited forms, by other disciplines (Vrasti 2007). Marcus $(1995,2013)$ is a leading scholar in the conceptualization of a methodology that meets the challenge of accessing multiple alternative narratives, and in enabling an ethnographic approach to reflect global patterns and connections. The approach acknowledges and makes use of macrotheoretical concepts (here, what we might consider 'global' concepts), but does not rely on them for the framing of local subjects (1995, 96). Instead, concepts are presented tentatively, open to change and reshaping through the detailed experience of the 'local'. Marcus writes that "[i] ust as this mode investigates and ethnographically constructs the life-worlds of variously situated subjects, it also ethnographically constructs aspects of the system itself through the associations and connections it suggests among sites" $(1995,96)$. In this approach, the global is understood as emergent from these connections $(1995,99)$; the local is productive of the global, and not distinct from it. Indeed, he argues that there is potential for the macro-level to be disrupted, as the global is actively created and constituted not as a separate sphere, but as a network of connections between two distinct contexts.

The stakes here are significant; they are about how we understand the 'reality' of the world. Milliken $(2001,147)$ discusses the role of "authorized speakers" in defining discourses, setting terms, and framing common senses; they determine the dominant narrative and its permutations. In a study of the politics of migration, the "authorized speakers" are representatives of the sovereign power - policy makers, practitioners and authorities - who enact and govern borders, certainly, but who are also implicated in the reproduction of dominant narratives of security, the system of states, and the interplay between borders, citizenship, and belonging. As Bleiker $(2000,24)$ argues, however, discourses are not monolithic; they are often thin, unstable and full of cracks. The dominant narrative sets the contexts and frameworks of border politics; the narratives of 'unauthorised speakers' contest this in dissonant voice to reveal these cracks, and suggest what they may mean within migration and border regimes.

A narrative approach that authorises speakers recognises the awareness that the subaltern have of the powerlessness of their position, and their generation of knowledge from their daily material experiences. The ways in which the local is caught within discursive practices and an order that delineates their 'reality' are manifest in narrative (Bleiker 2000, ch. 7). Bleiker highlights that discursive practices - narratives, symbols, shared meanings and understandings shape our world from a variety of subject positions. Most importantly this entails that the borderscapes, interstices, and overlapping structures and regimes that create migration realities are as much shaped by the migrants that move through them as they are by policy makers and practitioners that guard the borders and regulate these mobilities. Moreover, migrants are aware 
of their own position within this space; they are not caught as blind, mute and passive objects, but as active, engaged and meaningful subjects. A study that does not access migrant narratives, therefore, will be absent these engagements and meanings and will, necessarily, be incomplete.

\section{Narration and Translation}

A narrative approach has the potential to reveal patterns of similarity and difference across multiple global sites, and multiple stories told about the shape and experience of the world. The patterns give us insight and deeper understandings of the political dynamics that shape our world-politics that are encountered 'locally', but that have global implications, and that fracture the distinctions between local and global. A narrative approach embraces a certain methodology - an epistemological understanding of how research is/should be actively carried out at a metatheoretical level (Aradau et al 2015b) - that is committed to an engaged, situated, and contextual understanding of research that is led by participants themselves in a research practice that is strongly characterized by reflexivity. It recognizes the role and impact of the researcher, situating her as part of the project and as the author, perhaps, of the connections and patterns that, to draw on Buroway (2001), 'localize' the global. The narratives themselves, however, are authored by the participants.

To illustrate: on the borders of Spain at the Melilla enclave, and in the near-by Moroccan city of Oujda, my field work comprised lengthy conversations with irregular migrants who were seeking entry to Europe and observation of their daily lives in the autonomous camp on the University campus in Oujda, and in the city of Melilla for those who had successfully crossed the fence. We spoke on the front doorsteps of university buildings and houses, in cafés on the street, in school rooms, and on one memorable occasion inside a drain culvert. The migrants I engaged with, most of whom were from sub-Saharan Africa, shared stories of their journeys over years, their challenges, their encounters with border guards and with security forces, and their experiences of being irregular or, often, 'illegal.' Six months later, I sat across a bolted-down picnic table from a detained asylum seeker in Villawood detention centre in Sydney, Australia. On hunger strike, he was engaged in the last stages of his appeal against deportation. As had been the case in Spain, he shared with me stories of his journey, his challenges and struggles for recognition, and his daily strategies for survival first as an undocumented, racialized migrant (his visa had lapsed), and then as an asylum seeker in the prison-like detention centres of Australia.

In both sites - which, on the surface, were vastly different in context and experience - similar themes emerged; from the particular and the local, broad patterns emerged that have global implications. Individuals spoke of feeling temporary, and of feeling that this was a permanent status, regardless of where they were or how long they had been there. They spoke of conscious decisions to defy border guards, to return again after being deported, to evade visa regulations, and to time asylum applications strategically given their understanding of both national and international law. They used the language of rights, and they refused to be silent. They spoke of the freedom of movement, adopting the language of a human rights discourse, and of their rights to protection, and to make a better life for themselves. And, finally, they spoke of connections, of working together with other migrants to make their journeys, to understand the laws and regimes they encountered, and to resist the laws and rules they perceived as telling them to be invisible, and to be silent. The experiences of irregular migration and border crossing were something they held in common across time and space, and they expressed these as conscious and powerful narratives that were constructive of a global politics of asylum and irregular migration against state regimes of border control. 
These patterns emerged through stories. Krumer-Nevo and Sidi argue that narrative is a particular mode of presentation that locates the participant within the context of a story, situating the account in the context of a time and place. What is revealed, however, is not simply descriptive detail, but the intrapersonal reality of the narrator, and the intersubjective context in which she exists $(2012,301)$. Narrative can be understood as a mode of representation that is discursive, and so non-theoretical - as simply stories that are told, but that are consciously constructed as representative of a 'reality' beyond the construction (Soreanu 2010, 384). As Somers observes, however, scholars of narrative theory have also argued that they are epistemological and ontological. Through narrative, we understand our social worlds and, importantly, we also actively constitute our social identities $(1994,606)$. Narratives are used to define who we are (Somers 1994, 618). Spector-Mersel writes: "[i]f a sense of identity is attained through the stories we tell ourselves and others, not only is identity expressed in narrative, but also importantly, it is also constructed by it" (2011). I would push this analysis beyond the construction of identity to our understandings of political subjectivity and agency. If agents act in the world, exert control over it, and make choices, these actions, controls, and choices are all given meaning through how they are narrated. Narrations need not be public; they may, in fact, be internal to individual actors. They are nevertheless present, and they tell us what the otherwise abstract concepts we use to describe the world actually mean. As individual as they may be, they nevertheless create and shape our world; they give meaning to the global, and are an essential site of inquiry for international relations and international political sociology. For Somers, we cannot interpret social action, or political action, without emphasizing ontology, social being, and identity - and access to these dimensions is enabled by narrative inquiry which renders understanding by connecting the different parts to a larger network of relationships through intersubjective practices (Somers 1994, 616). In its entirety, this understanding of action is flexible, adaptable, and ever-changing in response to context and circumstance. It resists fixity. It is not a thing, but a dialogue; it is a practice, as are the strategies and inquiries we undertake to access it.

Latour argues that the challenge of empirical work is "how to study things... or, rather, how to let the actors have some room to express themselves" (2004; Bueger and Mireau 2015, 120). Understanding narrative as central to research methods does precisely this; it understands the empirical as constructed, and becomes, then, a method that creates space for multiple, relational constructions. It similarly enables multiple representations of politics, unpacking the fixed holistic understanding of the global into a fluid and multiply-informed manifestation of relations, fracturing the global into its constitutive parts.

The challenge of understanding the local as something that is constitutive of the global, and not separate and limited, is an issue of how the material is represented. Somers argues that difficulty in narration is related to an absence of usable forms of symbolic representation $(1994,630)$; it is the difficulty of constructing a narrative that can be heard, and understood, and is related to access to concepts and languages that make sense in the mobilization of the self. The stories we tell, in other words, must make sense to others. For Somers, this in part explains difficulties faced by marginalized groups in constructing social identities, and so our collective inability to acknowledge and understand, in her work, female subjectivity (Somers 1994, 630). The same might be said about the subaltern, or those who do not 'fit' within the categories and concepts that we mobilize in our research. Somers writes: "[t]he narrative approach to identity thus addresses the incoherencies of theories of action that leave vast numbers of social actors and social practices thoroughly unaccounted for" $(1994,624)$. By giving these subjects the 'room', as Latour demands, to express themselves, however, we can begin to witness the production of counter-narratives; "getting heard requires new theories" (Somers 1994, 610), and new theories cannot be generated in the absence of understanding what is hitherto unheard, uncounted, and 
unacknowledged. New theory needs new knowledge; new manifestations of the global need new entanglements of the local. We need new stories.

Research that engages with irregular migration as a political phenomenon is particularly attentive to these dynamics. Migration is an excellent illustration of the ways in which the 'global' is formed of negotiations and entanglements of the 'local', producing fractured and multiple experiences that nevertheless transgress and transcend boundaries in dynamic connections and patterns that inform the dominant narratives that shape our political world. Cvajner and Sciortino, however, argue that critical theorists tend to define irregular migration only in relation to political will, producing an undifferentiated category of the excluded $(2010,395)$. They raise a key question for migration scholars: "If the irregular migrant is defined as homo sacer, how is it possible that hundreds of thousands of migrants treat their condition as a practical problem to be managed according to a logic of expediency?" (Cvagjner and Sciortino 2010, 395). This, indeed, is precisely what was made clear in the narratives across multiple sites in my own field research; far from the abject, excluded figure of homo sacer, migrants are powerful actors in their own right. There is a tension in how we conceptualize migrants as political actors, and how they actually experience their condition. Even work that does focus on the manifestations and mobilizations of political will - on the autonomous crossing of borders in defiance of state regulation and security practices, for example (see: Mezzadra 2004; Rygiel 2008; Khosravi 2010) - faces this difficulty in that dimensions of the migrants' lives and perspectives go not simply unaccounted for, but often unnoticed. Without accounting for the full narrative of the migrants themselves, we tend to focus only on the single, specific moment of border crossing and so we miss the wider picture and the longer journey. An ethnographic or narrative approach that focuses on participant-led research enables a wider accounting for what 'counts' and what is 'included' in the 'data' gathered, and begins to provide us an answer to this challenge.

I argue that a narrative-led approach must also be participant led. In this, participants themselves are recognized as active authors of their own stories, literally authorizing their voices in the construction of wider understandings. This is not simply a process of recognition, and necessarily involves dynamics of what I am calling here interpretation and translation. The issue of interpretation has been widely explored, particularly in post-colonial theoretical approaches. Particularly important is Spivak, who asserts that the dynamics of interpretation, which she terms re-presentation: 'the subaltern cannot speak' (Spivak 1988). If we take Spivak's cautions seriously - which we should - the implication is that research is never free from interpretation. That interpretation occurs in the final stages of research, in the writing up, is reasonably wellestablished. Analysis is, at its core, a process of interpretation and presentation. When discussing narrative in ethnographic work in particular, Dauphinee $(2010,803)$ asks if there is a possibility of narrative truth; "whether anyone could actually apprehend, process, signify, and render it in speech or text or microform." She highlights in important ways the limits of the academic voice, while also pointing out that, as researchers, we play a significant role on what counts as knowledge, through a "narrative privilege" that authorizes or de-authorizes certain stories (806-807). In seeking an ethical practice for research, Dauphinee demands that we are attentive to how we write others. "What is at stake here is not the objective veracity of any particular claim, but rather the question of how that veracity is generated, and by whom" (2010, 807). What we choose to focus on as researchers is determined by what we have identified as relevant, important, and interesting; this is informed directly by our interpretation of these values. Even in the process of hearing and seeing interpretation is occurring. Particularly when digital recording methods are not used, how information is presented and recorded during the field research practice is an interpersonal, dialogical, and highly mobile practice this is not a oneway recording of truth, but a two way conversation. In it is in this conversation that what I am calling 'translation' occurs, and, importantly, I argue that translation is undertaken not by the researcher, but by the participant. The researcher interprets and represents the data through 
analysis and writing. The data itself - the narrative - is translated into this narrative in an active, conscious representation of self by the participant.

Narratives are shaped, framed and expressed in particular terms. To borrow from Benjamin (1991), translation cannot be done if one does not understand the original. The distance between the researcher and the participant is such that this understanding of the 'original' will never be congruent, and never be fully achievable. For Balibar, this is "war" - a conflict between the "irreducible, unspeakable, 'différend' with the Other... that can be displaced but not abolished" (2010, 317); it is Dauphinee's (2010) challenge of narrative truth, and the necessary incompleteness of any representation of the 'Other' (Spivak 1988). Haraway argues that "[t]ranslation is always interpretive, critical, and partial" $(1988,589)$. It is delivered in a certain context, and in response to certain circumstances. The presence of the researcher is part of these circumstances, as are the desires of the participants and the wider context of their experiences. The narrative of another is never fully accessible. It is always received via translation.

What we are faced with is the task of how to encompass this understanding of narrative translation and interpretation such that it is not understood as a problem that undermines the research, but instead as a valuable practice of dialogue and, I argue, of potential collaboration and co-authorship. The cautions that the stories we hear from participants - particularly from marginalized participants - may be manipulated and be somehow 'untrue' fail to recognize a central component of this dynamic. That we may be told 'what we want to hear' is far better expressed as 'what they think we want to hear'; the narratives that are shared are always rooted in the context of the interpersonal encounter and the wider context as perceived and understood by the participants. Moreover, the shaping of a narrative - for whatever reasons - is a political act. It is a world-creating act. If we can recognize this as a practice, abandoning the notion that narratives are objective artefacts that can be unearthed through the universal tools of method, there are opportunities to understand narrative research as a dialogue that calls into being particular understandings and possibilities.

In part because this practice of translation is so fluid, dynamic, and ultimately inaccessible, the temptation could be to ascribe to methods that are rooted in narrative practice, the status of 'fiction' (Clifford 1986). Narratives seem unverifiable, unreliable - irreplicable. They are, so the logic goes, too subjective for rigorous social science and, crucially, cannot then be the foundation for any useful or productive theory of the social/political worlds. It is this that renders the complex interplay between the local and the global unreadable; that fixes the two scales as distinct, and as unrelated, or unrelatable, in research. And yet, for many scholars, narrative approaches are the key methods through which non-dominant voices and perspectives can be represented in research; they are crucial for incorporating subjugated or marginalized knowledges into our understandings and shaping of the world we live in. Ortner writes that it seems "grotesque to insist on the notion that the text is shaped by everything but the lived reality of the people whom the text claims to represent" $(1995,188)$. It is similarly grotesque to believe that the global is accessible without consideration of local dimensions which it both created and is created by.

The absurdity of rendering such 'local' narratives as unreliable and inadmissible is revealed by the extent to which we do continue to define 'local' by way of the 'limited' knowledges of the excluded, but considered the 'informed' knowledges of the expert to be 'global'. This is despite the same methods being applied. Ortner writes that "absolute fictionality and absolute silencing are impossible not only because those being written about forced themselves into the author's account but also because there is always a multiplicity of accounts" (Ortner 1995, 190). In the same way that expert knowledge is upheld and accepted by its commerce - by its broad 
circulation, general acceptance achieved by frequent repetition, by multiplicity - the same is possible for the subaltern if we can accept that the connections and intersubjective relations of the local are constitutive and formative for the global. If we step away from the assumption that the experience of the marginalized is too local, too specific, too isolated to contribute to any broad understanding, these knowledges become authoritative, and their narratives audible.

De Fina writes that "to characterize stories that construct the experience of under-privileged groups, we need to be wary of accepted categories about story structure, and to be attuned to the specific resources that members of these groups put into place in specific interactions in order to see how micro and macro social circumstances are articulated by them" $(2003,389)$. In other words, we must be aware and wary of imposing our own frameworks, meta-narratives and concepts upon the narratives we hear - and instead work towards listening to those that are being mobilized by the individual who is speaking. From the outset, this is a challenge. Any encounter with irregular migrants falls within a framework that is conditioned by a pre-existing structure where migrants are understood, as Balibar argues, as "more than foreigners" but instead as "absolute aliens" $(2010,319)$. The authorization of the irregular migrant narrative has nothing less than a transformation of normalized structures of political status at stake; to recognize their narratives as authoritative is to recognize them as agents. Eckl writes that "the researcher should also keep in mind that the people studied are agents themselves and, unless force or fraud are used toward them, they should have the capacity to help themselves" (2008, 193). This is an invocation against victimization, and is in the context of a discussion of what responsibility researchers have for the lives and circumstances of those they work with; it can be equally applied to research itself. Moreover, I argue that if we do so, we reveal a practice of interruption - a fracturing of the dominant narratives of global politics - that can enable new interventions in our conceptualizations of the world.

\section{Interruptions and Conclusions}

Accounting for, and engaging with, subjugated narratives, and recognizing research participants as authors, provides moments of interruption that generate the potential to disrupt the fixity of the master-narrative and its dominant concepts and relations. These interruptions are opportunities for intervention, and for change. They transgress the binary of local/global and reveal the social and political fault lines that inform everyday experiences and confrontations.

This notion of interruption is closely related to that found in Rancière's theory of the politics of dissensus (1999). For Rancière, politics is in itself interruption; what we normally think of as the everyday functioning of politics, of the generation of consensus and the generative practices of democracy are, for him, nothing more than policing. They are forms of management that functions to end, to exclude, politics. When these practices are interrupted, when in his terms 'the part that has no part' demands inclusion, recognition, voice, and participation, these ruptures to the 'normal' are what constitute politics. In this sense politics is a product of 'dissensus'; at their core is contestation and disruption, and a calling of the established order into question. Politics is about change, and it is a process that is always incomplete (Rancière 1999). This incompleteness is an important dimension to the understanding of the global as emergent and immanent, rather than as a fixed category separate from the local. The ruptures and interruptions of narratives that are otherwise inaudible challenge not only the everyday commonsenses of how we understand the world, but also the assumed practice of research itself. Rancière's interruption and dissensus are particularly useful in conceptualizing the political agency of refugees, asylum seekers, and irregular migrants. As 'the part that has no part', his framework actually situates them as the central political agents rather than as the powerless 
excluded, which is a useful antidote to the radical exceptionalism of the homo sacer, found particularly in Agamben (1998).

The notion of disagreement as politically productive is very useful, but there remains a tension with the experience of the particular. As Ulary notes, for Rancière the particular cannot 'standin' for the universal. Specific struggles, specific instances of repression or resistance, local experiences and narratives, do not establish constitutive connections for a 'universal' - which he seems to desire $(2011,24)$. In this, there is some insight; the operations of power are nowhere identical and, so, struggles are also unique. This does not mean, however, that the connections cannot be made. While for Rancière, the particular is limited in its political and resistive potential, understanding the ways in which the local is constitutive of the global challenges this account. Bigo argues that a general theory of power must be avoided; this is a key element to his criticism of Rancière. For Bigo, Rancière continues to seek spokespersons (2011, 232); he continues to seek fixity, or holism. Such a quest falls into a certainty trap, collapsing multiplicity and silencing interruption. As Soreanu argues, "acts of rupture in the established disciplinary repertoire of IR... craft more space for debate" $(2010,384)$. This space, crucially, is constituted by the rupture, and is shaped by it.

A call to take narrative politics seriously, and to recognize participants as authors, as subjects, is thus also a call to an ethical research practice that aspires towards change. For Marcus (2013), ethical doubt 'haunts' many moments of field research, and I argue that how we engage with our participants and the knowledges they produce partially answers these challenges. Haraway argues for 'situated knowledges' that are embodied, which are "against various forms of unlocatable, and so irresponsible, knowledge claims" (1988, 583). Such 'unlocatable' knowledge cannot be called to account for Haraway; research that is thus distanced and disconnected is irresponsible. This notion of irresponsibility reflects the criticism of the transparency of the absent researcher (cf Spivak 1988). "Positioning is, therefore, the key practice in grounding knowledge... [and] implies responsibility for our enabling practices" (Haraway 1988, 587). It is positioning, locating, and situating knowledges that enable the ruptures, the interruptions, of narratives - and that contain the struggles and resistance that are the core to changing conceptualizations and understandings of our world, and to the mutual manifestations of the local and global. Doty suggests that it is fruitful to look for practices and experiences of ethics in the "small interstices of both time and space that are often overlooked or deemed insignificant in policy debates" $(2006,55)$. In valourizing the everyday, she highlights the degree to which "fleeting moments" might create openings to the impossible that are nonetheless possible. These practices are not (necessarily) visible; they are not the 'big' politics of globalization. They are profoundly local in the most direct sense, but they matter. They shape, impact, and affect the global. For Haraway, "[s]truggles over what will count as rational accounts of the world are struggles over how to see" (1988, 587; emphasis in original). Further, they are struggles over what to see and, given the implications of translation discussed above, it must be emphasized that the answers will never be settled. Struggles over what counts and who speaks are struggles over what our research means. This situating of narratives and participants resists generalization and the production of a unitary identity or homogenizing understanding. It demands instead recognition of multiplicity and all of the productive tensions that it produces.

Moore observes, "lives are still locally lived" $(2004,72)$. She goes on, however, to argue that in the absence of empirical analysis, the global context is imagined, if not imaginary (Moore 2004, 72). We need local experiences, local knowledges, to give the global content. For Poulos, the core of a relational ethic of method is not "[t]his is what you should do now" - which understands method as given - but "[w] hat should I do now?" - which presents method as flexible, adaptable and dynamic $(2008,63)$. In this regard, the researcher must be willing to learn, 
and even to question her own project (Eckl 190). As Dauphinee calls for (2010), researchers must seek ways to be answerable to our participants.

In a global politics that are shaped by assumptions about the primacy of the nation-state, the unauthorized crossing of borders can be understood as an interruption of the sovereign power of the state. The political agency of irregular migrants disrupts our common understandings and assumptions of political agency and who can be a subject in the global world. Authorizing the narratives of research participants, and particularly those who are in a subjugated position, interrupts the practice of research itself, but it also activates it, revealing new opportunities for understanding how the global is constituted through and by the local, and how this constitution contains potentials for a reconfiguration of how we study and understand our world - and how we might change it.

\section{Bibliography}

Agamben, Giorgio (1998). Homo Sacer. (Stanford: Stanford University Press).

Aradau, Claudia, Jef Huysmans, Andrew Neal and Nadine Voelkner (2015a). "Introducing Critical Security Methods" in Aradau, Claudia, Jef Huysmans, Andrew Neal and Nadine Voelkner, eds., Critical Security Methods: New frameworks for analysis. Routledge (London): 1-22.

----, Martin Coward, Eva Herschinger, Owen D. Thomas and Nadine Voelkner (2015b). "Discourse, Materiality" in Aradau, Claudia, Jef Huysmans, Andrew Neal and Nadine Voelkner, eds., Critical Security Methods: New frameworks for analysis. Routledge (London): 57-84.

Balibar, Etienne (2010). “At the Borders of Citizenship: A Democracy in Translation?” European Journal of Social Theory 13(3): 315-322.

Bigo, Didier (2011). "Pierre Bourdieu and International Relations: Power of Practices, Practices of Power" International Political Sociology 5(3): 225-258.

---- and Mikael R. Madsen (2011). "Introduction to Symposium 'A Different Reading of the International': Pierre Bourdieu and International Studies” International Political Sociology 5(3): 219-224.

Bleiker, Roland (2001). “The Aesthetic Turn in International Political Theory.” Millennium 30(3): 509-533.

Brigg, Morgan and Roland Bleiker (2008). "Expanding Ethnographic Insights into Global Politics." International Political Sociology 2(1): 89-90.

Bourdieu, Pierre (1988). "Vive la Crise! For Heterodoxy in Social Science" Theory and Society 17(5): 773-787.

Bueger, Christian and Manuel Mireanu (2015). "Proximity" in Aradau, Claudia, Jef Huysmans, Andrew Neal and Nadine Voelkner, eds., Critical Security Methods: New frameworks for analysis. Routledge (London): 118-141.

Buraway, Michael (2001). "Manufacturing the global" Ethnography 2(2): 147-159.

Cvajner, Martina and Giuseppe Sciortino (2010). “Theorizing Irregular Migration: The Control of Spatial Mobility in Differentiated Societies" European Journal of Social Theory 13(3): 389404.

De Fina, Anna (2003). "Crossing Borders: Time, Space, and Disorientation in Narrative" Narrative Inquiry 13(2): 367-391.

Dauphinee, Elizabeth (2010). "The ethics of autoethnography" Review of International Studies 36(3): 799-818.

Doty, Roxanne Lynn (2006). "Fronteras Compasivas and the Ethics of Unconditional Hospitality" Millennium: Journal of International Studies 35(1): 53-74. 
Eckl, Julian (2008). "Responsible Scholarship After Leaving the Veranda: Normative Issues Faced by Field Researchers - and Armchair Scientists." International Political Sociology 2(3): 185-203.

Ghorashi, Halleh (2007). "Refugee Voice, Giving Silence a Chance: The Importance of Life Stories for Research on Refugees." Journal of Refugee Studies 21(1): 117-132.

Haraway, Donna (1988). "Situated Knowledges: The Science Question in Feminism and the Privilege of Partial Perspective." Feminist Studies 14(3): 575-599.

Harding, Sandra (1998). Is Science Multicultural? Postcolonialisms, Feminisms, and Epistemologies. (Bloomington: Indiana University Press).

Johnson, Heather L. (2014). Borders, Asylum and Global Non-Citizenship: the Other Side of the Fence. Cambridge: Cambridge University Press.

Khosravi, Shahram (2010). Illegal Traveller: an An Auto-Ethnography of Borders. (New York: Palgrave MacMillan).

King, Gary, Robert O. Keohane and Sidney Verba (1994). Designing Social Inquiry: Scientific Inference in Qualitative Research. (Princeton: Princeton University Press).

Marcus, George E. (2013). "Experimental forms for the expression of norms in the ethnography of the contemporary" HAU: Journal of Ethnographic Theory 3(2): 197-217.

---- (1995). "Ethnography in/of the World System: The Emergence of Multi-Sited Ethnography." Annual Review of Anthropology 24: 95-117.

Mezzadra, S. (2004). “The Right to Escape.” Ephemera, 4(3), 267-75.

Milliken, Jennifer (2001). "Discourse Study: Bringing Rigour to Critical Theory" in Karin M. Fierke and Knud Erik Jorgensen, eds.. Constructing International Relations: The Next Generation. (Armonk: M.E. Sharpe): 136-159.

Moore, Henrietta L. (2004). "Global Anxieties: Concept-metaphors and pre-theoretical commitments in anthropology" Anthropological Theory 4(1): 71-88.

Ortner, Sherry B. (1995). "Resistance and the Problem of Ethnographic Refusal." Comparative Studies in Society and History 37(1): 173-193.

Paolini, Albert J. (1999). Navigating Modernity: Postcolonialism, Identity and International Relations. (Boulder: Lynne Reiner Publishers).

Paulos, Christopher N. (2008). "Narrative Conscience and the Autoethnographic Adventure: Probing Memories, Secrets, Shadows, and Possibilities." Qualitative Inquiry 14(1): 46-66.

Rajaram, Prem Kumar (2002). “Theodor Adorno’s Aesthetic Understanding: An Ethical Method for IR?” Alternatives 27(3): 351-373.

Rancière, Jacques (1999). Dis-agreement: Politics and Philosophy (Minneapolis: The University of Minnesota Press).

Routledge, Paul (1996). "The Third Space as Critical Engagement." Antipode 28(4): 399-419.

Somers, Margaret R. (1994). "The Narrative Constitution of Identity: A Relational and Network Approach" Theory and Society 23(5): 605-649.

Spivak, Gayatri Chakravorty (1988). "Can the Subaltern Speak?" in Cary Nelson and Lawrence Grossberg, eds., Marxism and the Interpretation of Culture. (Urbana: University of Illinois Press).

Ulary, Georganna (2011). "Rancière, Kristeva and the Rehabilitation of political life." Thesis Eleven 106(1): 23-38.

Vrasti, Wanda (2008). "The Strange Case of Ethnography and International Relations" Millennium - Journal of International Studies 37(2): 279-301 